\title{
Combination of nigericin with cisplatin enhances the inhibitory effect of cisplatin on epithelial ovarian cancer metastasis by inhibiting slug expression via the Wnt/ $\beta$-catenin signalling pathway
}

\author{
BIN ZHOU ${ }^{1,2}$, CHANGLIN WANG ${ }^{2}$, XIAOBEI LIU ${ }^{3}$, BIN WU $^{2}$, \\ JIANWEI $\mathrm{LI}^{4}$, SHUJUAN YAO ${ }^{5}$ and SHIQIAN ZHANG ${ }^{1}$

\footnotetext{
${ }^{1}$ Department of Gynecology, Qilu Hospital, Cheeloo College of Medicine, Shandong University, Jinan, Shandong 250012;

Departments of ${ }^{2}$ Gynecology and ${ }^{3}$ Reproduction and Genetics, Taian City Central Hospital;

${ }^{4}$ Department of Pharmacy and Laboratory Medicine, Taishan Vocational College of Nursing, Taian, Shandong 271000;

${ }^{5}$ Department of Gynecology, Jining Medical University Affiliated Tengzhou Central People's Hospital,

Tengzhou, Shandong 277599, P.R. China
}

Received November 25, 2020; Accepted May 28, 2021

DOI: $10.3892 / 01.2021 .12961$

\begin{abstract}
Epithelial ovarian cancer (EOC) is the most lethal cancer among female genital tumours. Standard therapies, including postoperative chemotherapy, exhibit high proportions of recurrence and resistance. Novel therapeutic strategies are combined with chemotherapy. Emerging studies have demonstrated that nigericin, an $\mathrm{H}^{+}, \mathrm{K}^{+}$and $\mathrm{Pb}^{2+}$ ionophore, exhibits promising anticancer activity in various types of malignancy, such as colorectal and epithelial ovarian cancer. Our previous study suggested that nigericin could regulate EOC cell proliferation, migration and invasion, and may be a novel chemotherapy candidate for EOC. However, to the best of our knowledge, the effects of combined therapy with cisplatin, and the associated underlying mechanisms, are not yet fully understood. The present study aimed to clarify the effects of combined chemical therapy with nigericin and cisplatin on EOC cells and to reveal its mechanism. Wound healing, Transwell, cell viability and colony formation assays were used to measure the migration, invasion and proliferation of EOC cells. Western blotting was used to detect protein expression. A slug overexpression lentivirus was used to create a slug overexpression model in SK-OV-3 cells. Small interfering RNA was used to knock down slug expression. Nigericin combined with cisplatin enhanced the inhibitory effects of cisplatin on the
\end{abstract}

Correspondence to: Dr Shiqian Zhang, Department of Gynecology, Qilu Hospital, Cheeloo College of Medicine, Shandong University, 107 West Wenhua Road, Jinan, Shandong 250012, P.R. China

E-mail: r370112@126.com

Key words: nigericin, epithelial ovarian cancer, slug, metastasis, combined therapy migration and colony formation of EOC cells. Nigericin also enhanced the inhibitory effects of cisplatin on the expression levels of MMP7, as well as the inhibitory effects of cisplatin on the expression levels of $\beta$-catenin and GSK-3 $\beta$, indicating that nigericin and cisplatin regulated in the $\mathrm{Wnt} / \beta$-catenin signalling pathway. When slug was knocked down, the effect of nigericin was weakened. Overexpression of slug could repress the inhibitory effect of nigericin on the Wnt/ $\beta$-catenin signalling pathway. Furthermore, nigericin inhibited slug expression by enhancing its modification through small ubiquitin-like modifiers (SUMOs; referred to as SUMOylation). Overall, the present results demonstrated that nigericin combined with cisplatin might serve as a novel therapeutic strategy in patients with metastatic EOC because the combined therapy had higher effectiveness than single drug use. The underlying mechanism of combined therapy maybe the enhanced inhibitory effect of slug through its nigericin-induced SUMOylation.

\section{Introduction}

Ovarian cancer $(\mathrm{OC})$ is the 7 th most diagnosed cancer among women worldwide and the 10th most common in China (1). Additionally, $\sim 90 \%$ of all OCs are epithelial in terms of origin, that is, epithelial OC (EOC) (2). Since EOC is a chemo-responsive tumour, which responds well to platinum, including cisplatin, the standard therapy for EOC remains surgery combined with chemotherapy $(3,4)$. Platinum-taxanes doublet is the standard treatment in EOC (4). However, the prognosis of patients with EOC remains poor $(2,5,6)$. Firstly, almost $80 \%$ of patients develop tolerance to standard platinum therapy and will recur with a resistant disease (5). Secondly, the 5-year overall survival rate has remained at only $30-40 \%$ worldwide since 1995 (2). Furthermore, $>70 \%$ of patients are diagnosed with advanced-stage disease and would suffer from multiple metastases, migration and invasion of the tumour, which eventually lead to death (6). 
Although a meta-analysis has provided evidence of the benefits of combination-platinum over single-agent platinum (7), platinum combinations inevitably lead to greater toxicity and similar antitumour molecular mechanisms, which are more likely to lead to the development of platinum resistance (8). Therefore, searching for novel chemical drugs with diverse antitumour molecular mechanisms that could be combined with platinum is an improved selection approach for EOC combination chemotherapy (9).

Nigericin is an $\mathrm{H}^{+}, \mathrm{K}^{+}$and $\mathrm{Pb}^{2+}$ ionophore derived from Streptomyces hygroscopicus $(10,11)$. It is widely used as an antibiotic agent in chickens (12). Nigericin has exhibited potent anticancer activities in several types of cancer $(12,13)$, as well as in resistant cancer stem cells $(14,15)$. Nigericin sensitizes cancer cells and exhibits a synergistic effect with other anticancer drugs, thereby leading to improved efficacy of these drugs (16). This enhanced efficacy is mostly associated with nigericin's ability to reduce internal $\mathrm{pH}$ in an acidic tumour microenvironment $(10,13)$. Our previous study demonstrated that nigericin could inhibit epithelial-mesenchymal transition (EMT) during cell invasion and metastasis via the canonical Wnt/ $\beta$-catenin signalling pathway (17), and may be a chemotherapy option combined with platinum for patients with EOC.

However, whether chemotherapy that combines nigericin and platinum has better therapeutic effects than single chemical drug therapy and the molecular mechanism of nigericin triggered by the combination chemotherapy remain unclear. Therefore, the present study aimed to explore the aforementioned questions in human EOC cells.

\section{Materials and methods}

Cell lines and cell culture. Human SK-OV-3 and A2780 EOC cell lines were used in the present study. SK-OV-3 cells were obtained from The Cell Bank of Type Culture Collection of The Chinese Academy of Sciences, and A2780 cells were purchased from American Type Culture Collection. SK-OV-3 cells were cultured in McCoy's 5A medium (Thermo Fisher Scientific, Inc.), while A2780 cells were cultured in RPMI-1640 medium (Thermo Fisher Scientific, Inc.). Both media were supplemented with $10 \%$ FBS (Thermo Fisher Scientific, Inc.), $100 \mathrm{U} / \mathrm{ml}$ penicillin and $100 \mathrm{U} / \mathrm{ml}$ streptomycin (Sigma-Aldrich; Merck KGaA). Both cell lines were cultured at $37^{\circ} \mathrm{C}$ in a humidified atmosphere with $5 \% \mathrm{CO}_{2}$. The cells were routinely grown until they reached $80 \%$ confluence and then subcultured or plated for experiments.

Drugs and antibodies. Nigericin and cisplatin were obtained from Sigma-Aldrich; Merck KGaA. Nigericin (25 mM stock) was dissolved in DMSO. Cisplatin (1 mM stock) was dissolved in normal saline $(0.9 \% \mathrm{NaCl})$. Both stock solutions were stored as aliquots at $-20^{\circ} \mathrm{C}$. DMSO served as a vehicle control. The following primary antibodies were used at the dilution recommended by the manufacturer $(1: 1,000)$ and purchased from Cell Signaling Technology, Inc.: Rabbit anti-Axin-2 (cat. no. 2151), rabbit anti-MMP7 (cat. no. 71031), rabbit anti-vimentin (cat. no. 5741), rabbit anti-tubulin (cat. no. 2148), rabbit anti- $\beta$-catenin (cat. no. 25362), rabbit anti-slug (cat. no. 9585), rabbit anti-E-cadherin (cat. no. 3195) and rabbit anti-small ubiquitin-like modifier 1 (SUMO1; cat. no. 4930). Mouse anti-GSK3 $\beta$ (cat. no. sc-377213) was used at a 1:200 dilution, and purchased from Santa Cruz Biotechnology, Inc. Goat anti-mouse IgG (HRP) (ZB-2305) and Goad anti-rabbit IgG (HRP) (ZB-2301) were used at a dilution of 1:2,500, and were purchased from ZSGB-BIO, Inc. (http://www.zsbio.com/).

Wound healing assay. SK-OV-3 cells were plated into 6-well plates and allowed to reach confluence at $90 \%$. Subsequently, a $200-\mu 1$ pipette tip was used to scratch constant-diameter wounds in the confluent monolayers. Cells were rinsed twice with PBS and incubated with serum-free medium for $24 \mathrm{~h}$ at $37^{\circ} \mathrm{C}$ to weaken the interference effects of cell proliferation. Cells in different wells were treated with different concentrations of drugs (nigericin or cisplatin) in the medium (5 and $20 \mu \mathrm{mol} / \mathrm{ml}$ ), shown in each figure. The wounds were imaged at 0 and $24 \mathrm{~h}$ after scratching under an inverted microscope (NIB-100F; Ningbo Yongxin OPTICS CO., LTD.).

Transwell assay. Boyden chambers with $8-\mu \mathrm{m}$ pore filters were used. SK-OV-3 and A2780 cells treated with DMSO or combined drugs at different concentrations in McCoy's 5A medium and RMPI-1640 medium, respectively, without FBS, were plated in the upper chambers, which were pre-coated with $25 \%$ Matrigel in medium at $37^{\circ} \mathrm{C}$ for $4 \mathrm{~h}$. The lower chambers were filled with culture medium supplemented with $10 \% \mathrm{FBS}$. After incubation for $24 \mathrm{~h}$ at $37^{\circ} \mathrm{C}$, cells were fixed in $4 \%$ paraformaldehyde for $20 \mathrm{~min}$ at room temperature, then non-migrating cells in the upper chamber were completely removed using a cotton swab. Cells that migrated to the lower surface of the membrane were stained with $0.5 \%$ crystal violet for $3 \mathrm{~min}$ at room temperature. These cells were using an inverted microscope and quantified by counting the number of stained nuclei in five random fields using ImageJ (1.42; National Institutes of Health). Each assay was repeated twice.

Cell viability assay. The viability of EOC cells treated with nigericin in combination with cisplatin was analysed using a Cell Counting Kit-8 (CCK-8; cat. no. CK04; Dojindo Molecular Technologies, Inc.) according to the manufacturer's protocol. Briefly, SK-OV-3 and A2780 cells were plated into a $96 \%$ well plate at a density of 4,000 cells/well in a final volume of $100 \mu \mathrm{l}$ medium and cultured under normal conditions for $24 \mathrm{~h}$. Subsequently, nigericin $(5 \mu \mathrm{M})$ and cisplatin $(5 \mu \mathrm{M}$ or $20 \mu \mathrm{M}$ ) were added to each well of the plates using DMSO as a vehicle control. Subsequently, $10 \mu \mathrm{l}$ CCK-8 reagent was added to each well post-incubation for $48 \mathrm{~h}$, and the cells were incubated and shielded from light for $1 \mathrm{~h}$ at $37^{\circ} \mathrm{C}$. Cell viability was calculated by measuring the absorbance at $450 \mathrm{~nm}$ using a microplate reader (Bio-Rad Laboratories, Inc.). Growth inhibition was calculated as a percentage of the vehicle control. Experiments were performed three times and the data are presented as the mean \pm SD of five wells per treatment.

Colony formation assay. SK-OV-3 and A2780 cells were plated into a $6 \%$ well plate at a density of 1,000 cells/well and grown under normal conditions for $12 \mathrm{~h}$. Then, cells were treated with nigericin and cisplatin at 5 or $20 \mu \mathrm{M}$, as shown in each figure. Following incubation under normal conditions 
for 14 days, the cells were fixed with $4 \%$ paraformaldehyde for $20 \mathrm{~min}$ at room temperature, and then stained with $0.5 \%$ crystal violet (Beyotime Institute of Biotechnology) for $30 \mathrm{~min}$ at room temperature. Subsequently, the number of cell colonies was counted under an inverted microscope.

Luciferase reporter assay. The TOPflash/FOPflash reporter assay was used for monitoring the activity of the Wnt/ $\beta$-catenin signalling pathway in SK-OV-3 and A2780 cells. The pTOPflash vector (cat. no. D2501) and pFOPflash vector (cat. no. D2503) were purchased from Beyotime Biotechnology and constructed based on pGL6-TA, according to the product specifications. The pTOPflash vector contains a firefly luciferase gene under the control of two T cell factor (TCF) response elements with three repeats located upstream of minimal TA viral promoter. The negative control pFOPflash vector contains a firefly luciferase gene under the control of two mutant TCF response elements with three repeats located upstream of minimal TA viral promoter. SK-OV-3 and A2780 cells (5x10 4 cells/well) were seeded into 48-well plates and incubated overnight before transfection. The cells were co-transfected with reporter plasmid (200 ng pTOPflash or pFOPflash) and control vector (20 ng pRL-TK, cat. no. D2760, Beyotime Biotechnology) using Lipofectamine ${ }^{\circledR} 2000$ (Invitrogen; Thermo Fisher Scientific, Inc.). At $4 \mathrm{~h}$ post-transfection, the culture medium was changed for complete medium and treated with nigericin and/or cisplatin at 5 or $20 \mu \mathrm{M}$. The SK-OV-3 or A2780 cells were cultured for $48 \mathrm{~h}$ in complete medium. Afterwards, the luciferase activity was measured using the Dual-Luciferase ${ }^{\circledR}$ Reporter Assay System (Promega Corporation) according to the manufacturer's protocol, and normalized for transfection efficiency using the corresponding Renilla luciferase activity. Reporter activity was calculated as a ratio of TOPflash to FOPflash. The experiment was performed in triplicate.

Transient knockdown. Transient gene/protein expression knockdown in SK-OV-3 cells was established by transfection with $50 \mathrm{nM}$ non-specific [negative control small interfering (siRNA): GCAAGCTGACCCTGAAGTT] or specific siRNA molecules targeting slug (slug-siRNA-1: 5'-CAAACG ACTTTGCAACTCC-3'; slug-siRNA-2: 5'-CCTCTTGGC ATACTCCTCT-3'), which were purchased from Generay biotech Co. Ltd. Cells were transfected with siRNAs using Lipofectamine ${ }^{\circledR}$ RNAiMAX Reagent (Invitrogen; Thermo Fisher Scientific, Inc.) as recommended by the manufacturer. Cells were analysed after $48 \mathrm{~h}$ at $37^{\circ} \mathrm{C}$. The cells were then harvested for RT-qPCR and western blot analysis.

Lentivirus-mediated overexpression. Slug-overexpressing SK-OV-3 and A2780 EOC cell lines were established via lentivirus transfection. A lentiviral vector encoding slug (LV-slug) and a negative control vector (LV-vector) were purchased from OBiO Technology (Shanghai) Corp., Ltd., and carried an enhanced green fluorescent protein reporter gene, EGFP. The lentiviral vector used for overexpression was named pSLenti-CMV-EGFP-3xFLAG-PGK-PuroWPRE according to the manufacturer's introduction. For slug exogenous overexpression, lentivirus containing LV-slug or the LV-vector were transfected into SK-OV-3 and A2780 cells using Polybrene $(5.0 \mu \mathrm{g} / \mathrm{ml})$ from OBiO Technology according to the manufacturer's protocol. Briefly, cells were seeded into a 6 -well plate $\left(1 \times 10^{5}\right.$ cells/well) for adherence. Then, the cells were transfected with lentivirus vectors (LV-slug or LV-vector) at a multiplicity of infection of 30 , in the presence of $5 \mu \mathrm{g} / \mathrm{ml}$ Polybrene at $37^{\circ} \mathrm{C}$. After $72 \mathrm{~h}$ of transduction, medium containing puromycin $(0.2 \mathrm{mg} / \mathrm{ml})$ was added to select stably transduced cells, and stable cell lines were screened for 3 weeks. Slug upregulation efficiency was assessed by western blotting.

Western blotting. Cells were washed with $1 \mathrm{X}$ PBS three times, and the total cell proteins were extracted using RIPA lysis buffer (Beyotime Institute of Biotechnology) with freshly added proteinase inhibitor cocktail and phosphatase inhibitor (Sigma-Aldrich; Merck KGaA) on ice for $15 \mathrm{~min}$ and centrifuged at $12,700 \mathrm{x} \mathrm{g}$ for $20 \mathrm{~min}$ at $4^{\circ} \mathrm{C}$. BCA (Sigma-Aldrich; Merck $\mathrm{KGaA}$ ) was used to determine the concentration of total protein of EOC cells. For western blot analysis, lysates (20 $\mu \mathrm{g} /$ lane) were subjected to $12 \%$ SDS-PAGE, and then the fractionated proteins were transferred to a PVDF membrane (ISEQ00010/IPVH00010; Millipore). The membrane was blocked in $1 \mathrm{X}$ TBS with $0.5 \%$ Tween-20 (TBST) with 5\% non-fat milk for $1 \mathrm{~h}$ at room temperature and then incubated with primary antibodies against axin 2, vimentin, tubulin, $\beta$-catenin, slug, E-cadherin, SUMO and GSK3 $\beta$, overnight at $4^{\circ} \mathrm{C}$. Next day, the membrane was washed with 1X TBST three times and incubated with the appropriate HRP-conjugated secondary antibodies for $1 \mathrm{~h}$ at room temperature. Positive immunoreactive proteins were detected using the Novex ${ }^{\mathrm{TM}}$ ECL Chemiluminescent Substrate Reagent Kit (Thermo Fisher Scientific, Inc.) to visualize signals and bands. The tubulin band served as a reference control.

Immunoprecipitation (IP) assay. In the IP assay, SK-OV-3 cells were cultured in $10-\mathrm{cm}$ dishes and incubated with nigericin or cisplatin (as shown in figures) for $48 \mathrm{~h}$ at $4^{\circ} \mathrm{C}$. Then, the cells were lysed with IP-buffer [Tris- $\mathrm{Cl}(\mathrm{pH} 7.5)$ $50 \mathrm{mmol} / \mathrm{l}, \mathrm{NaCl} 150 \mathrm{mmol} / \mathrm{l}, \mathrm{NP}-40$ 1\%, EDTA $5 \mathrm{mmol} / \mathrm{l}$, PMSF $1 \mathrm{mmol} / 1$, protease inhibitor (aprotinin $2 \mu \mathrm{g} / \mathrm{ml}$, leupeptin $2 \mu \mathrm{g} / \mathrm{ml}$, and pepstatin $7 \mu \mathrm{g} / \mathrm{ml}$ )] on ice for $30 \mathrm{~min}$, and centrifuged at $12,700 \times \mathrm{g}$ for $10 \mathrm{~min}$ at $4^{\circ} \mathrm{C}$. Then, the supernatant was transferred to new tubes immediately, and $50 \%$ protein $\mathrm{G}$ agarose was added with ratio of $100 \mu \mathrm{l}$ for a $1 \mathrm{ml}$ sample. The samples were shaken on horizontal shaker for $10 \mathrm{~min}$ at $4^{\circ} \mathrm{C}$, to eliminate non-specific binding proteins. Next, add $1 \mu \mathrm{g}$ anti-slug antibody (cat. no. 9585; Cell Signaling Technology, Inc.) and $50 \%$ protein $\mathrm{G}$ agarose (with ratio of $100 \mu \mathrm{l}$ for a $1 \mathrm{ml}$ sample solution) were added, and incubated on a horizontal shaker overnight at $4^{\circ} \mathrm{C}$, centrifuged at $3,000 \mathrm{~g}$ for $10 \mathrm{~min}$ at $4^{\circ} \mathrm{C}$, and the supernatants were discarded. The agarose was then collected and washed twice with IP buffer, then collected by centrifugation $\left(3,000 \mathrm{x}\right.$ f for $10 \mathrm{~min}$ at $\left.4^{\circ} \mathrm{C}\right)$, and detected by western blotting using anti-SUMO antibodies (cat. no. 4930; CST).

Statistical analysis.. Statistical analyses were performed using a statistical software package (SPSS 19.0; IBM Corp.). Data are presented as the mean \pm standard deviation. Statistical significances were determined by one-way ANOVA with Tukey's post hoc test for multiple comparisons. Unpaired Student's 
t-test was used to determine the statistical significance for two independent groups (cells treated with combined nigericin and cisplatin vs. cells treated with cisplatin only). $\mathrm{P}<0.05$ was considered to indicate a statistically significant difference.

\section{Results}

Nigericin combined with cisplatin enhances the inhibitory effect of cisplatin on the migration of EOC cells. To explore the effects of nigericin on promoting the inhibitory effect of cisplatin on the migration of EOC cells, nigericin combined with cisplatin was used to treat EOC cells, and wound healing and Transwell assays were performed. The results revealed that the inhibitory effect on the migration of EOC cells after the addition of nigericin was more significant compared with that of only cisplatin $(5 \mu \mathrm{M}$ nigericin and $5 \mu \mathrm{M}$ cisplatin vs. $5 \mu \mathrm{M}$ cisplatin; $5 \mu \mathrm{M}$ nigericin and $20 \mu \mathrm{M}$ cisplatin vs. $20 \mu \mathrm{M}$ cisplatin; Fig. 1A-C). Moreover, the promoting effect of nigericin on the inhibition of proliferation caused by cisplatin was significant compared with cisplatin treatment alone (Fig. 1D and E). These data suggested that nigericin might interact with/affect the migration pathway.

Nigericin combined with cisplatin enhances the inhibitory effect of cisplatin on the colony formation of EOC cells. The present study also used a colony formation assay to examine the long-term effects of nigericin combined with cisplatin on the proliferation of EOC cells. The results demonstrated that nigericin and cisplatin could inhibit colony formation. However, the combination of nigericin and cisplatin exhibited more significant inhibitory effects than cisplatin only on colony formation in SK-OV-3 and A2780 cells (Fig. 2). Overall, the combination of nigericin and cisplatin caused a significant reduction in migration and colony formation compared with the single cisplatin drug used in EOC cells. These data suggested that the combination of nigericin and cisplatin might inhibit the migration and proliferation of EOC cells effectively.

Nigericin combined with cisplatin regulates MMP expression and inhibits the Wnt/ $\beta$-catenin signalling pathway in EOC cells. MMPs are usually overexpressed in EOC cells and considered to be associated with metastasis (18). To determine whether nigericin combined cisplatin influenced MMP expression in EOC cells, the present study examined MMP7 expression in SK-OV-3 and A2780 cells using western blotting. Furthermore, E-cadherin and vimentin are markers of epithelial cells and mesenchymal cells, which serve important roles in the EMT, and EMT is essential for metastasis of EOC cells. A pervious study has demonstrated that nigericin could increase the expression levels of E-cadherin and decrease vimentin expression in EOC cells with a dose-response relationship via the $\mathrm{Wnt} / \beta$-catenin signalling pathway (12). The present study examined the combined effect of nigericin and cisplatin on the $\mathrm{Wnt} / \beta$-catenin signalling pathway. The results demonstrated that $5 \mu \mathrm{M}$ nigericin enhanced the inhibitory effect of cisplatin (5 and $20 \mu \mathrm{M}$ ) on MMP7 and Axin-2 expression (Fig. 3A and B). Nigericin $(5 \mu \mathrm{M})$ also enhanced the inhibitory effect of cisplatin $(5$ and $20 \mu \mathrm{M})$ on $\beta$-catenin and GSK-3 $\beta$ expression, thereby indicating the involvement of nigericin and cisplatin in the Wnt/ $\beta$-catenin signalling pathway by inhibiting its activation (Fig. 3C and D). Furthermore, when combined with cisplatin, nigericin could increase the expression levels of E-cadherin and decrease the expression levels of vimentin in EOC cells (Fig. 3C and D). Furthermore, luciferase reporter assays revealed that activation of the Wnt/ $\beta$-catenin pathway was markedly reduced by treatment with combined nigericin $(5 \mu \mathrm{M})$ and cisplatin (5 and $20 \mu \mathrm{M}$ ) compared with cisplatin alone (5 and $20 \mu \mathrm{M}$ ) in both SK-OV-3 and A2780 cells (Fig. 3E).

Nigericin combined with cisplatin enhances the inhibition of the Wnt/ $\beta$-catenin signalling pathway by inhibiting slug expression. Slug is a transcription factor, which is increased by the activation of the Wnt/ $\beta$-catenin signalling pathway (19). To determine whether slug was regulated by the combined effects of nigericin and cisplatin on the Wnt/ $\beta$-catenin signalling pathway, the present study firstly examined slug expression following the treatment of SK-OV-3 cells with nigericin and cisplatin by western blotting. The results revealed that nigericin combined with cisplatin inhibited slug expression (Fig. 4A). Subsequently, the expression levels of slug in SK-OV-3 cells treated with nigericin or cisplatin alone were detected, respectively. The results revealed that slug expression was decreased following treatment with nigericin in a concentration-dependent manner, while slug protein expression was slightly altered by cisplatin (Fig. 4B and C). Furthermore, when siRNA was used to suppress slug expression and the Wnt signalling pathway (Fig. 4D), the inhibitory effect was not as effective as that of treatment with $5 \mu \mathrm{M}$ nigericin shown in Fig. 2C. The inhibitory effect on the Wnt signalling pathway was more obvious when $5 \mu \mathrm{M}$ nigericin was added (Fig. 4E).

Subsequently, SK-OV-3-slug cells with stable overexpression of slug were generated (Fig. 5A) to rescue the phenotype induced by the combined therapy. The extent of the decreased expression of vimentin, GSK-3 $\beta$ and $\beta$-catenin, and the increase in E-cadherin was less in the SK-OV-3-slug cells, compared with SK-OV-3-vector cells with the same nigericin and cisplatin treatment. It is suggested that the inhibition of the combined effect on the Wnt/ $\beta$-catenin pathway could be reduced by the overexpression of slug (Fig. 5B). Furthermore, the inhibitory effect on the migration and colony formation was also decreased (Fig. 5C and D). A2780 cells with stable overexpression of slug were also generated (Fig. S1A). Similar results were observed in migration and colony formation assays following slug overexpression (Fig. S1B and C). These results suggested a pivotal role of slug in the combined therapy of nigericin and cisplatin suppressing EMT. They also implied the important role served by nigericin in the suppression of EMT in the combined therapy in EOC cells.

Nigericininhibits slug expression byenhancing its SUMOylation . Considering that nigericin could enhance the knockdown effect of siRNA on slug, nigericin may regulate slug expression in a post-transcriptional manner. Subsequently, the present study investigated whether nigericin degraded slug through SUMOylation in SK-OV-3 cells. The results demonstrated that nigericin, but not cisplatin, promoted the SUMOylation of slug (Fig. 6A) in a time-dependent manner (Fig. 6B). 

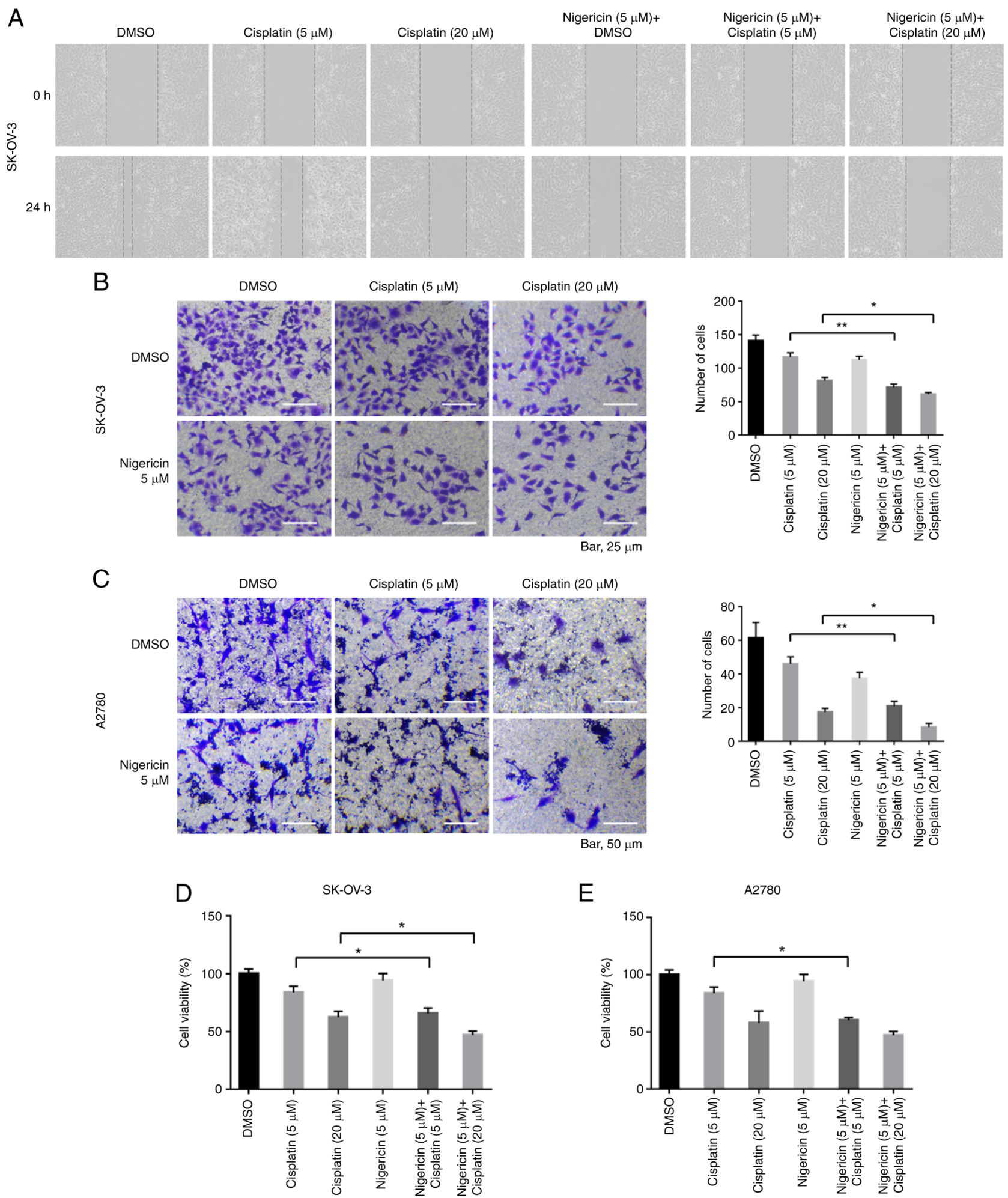

Figure 1. Combination of nigericin with cisplatin enhances the inhibitory effect of cisplatin on the migration of epithelial ovarian cancer cells. (A) Cell migration of SK-OV-3 was determined using a wound healing assay. Magnification, x100. (B) Migration of SK-OV-3 cells was determined using a Transwell assay. Magnification, $\mathrm{x} 200$. Scale bar, $25 \mu \mathrm{m}$. Data are presented as the mean \pm SD $(\mathrm{n}=3)$. (C) Migration of A2780 cells was determined using a Transwell assay. Magnification, $x 100$. Scale bar, $50 \mu \mathrm{m}$. Data are presented as the mean \pm SD (n=3). Viability of (D) SK-OV-3 and (E) A2780 cells was evaluated using a Cell Counting Kit- 8 assay, respectively. Data are presented as the mean $\pm \mathrm{SD}(\mathrm{n}=3)$. ${ }^{*} \mathrm{P}<0.05$ and ${ }^{* *} \mathrm{P}<0.01$.

\section{Discussion}

Although platinum is still the first-line therapy for post-operative chemotherapy (8), it is a major obstacle in the effective treatment of EOC that patients usually relapse with a tumour that is resistant to chemotherapy with cisplatin or carboplatin $(20,21)$. Therefore, exploring appropriate drugs that could be combined with platinum for post-operative chemotherapy instead of the single platinum used in dealing with EOC is urgent (9). A previous study has demonstrated that 
A

DMSO

$m$
$\substack{1 \\ 1 \\ 1}$
$\frac{1}{0}$

Nigericin

(5 $\mu \mathrm{M})$

MSO

B

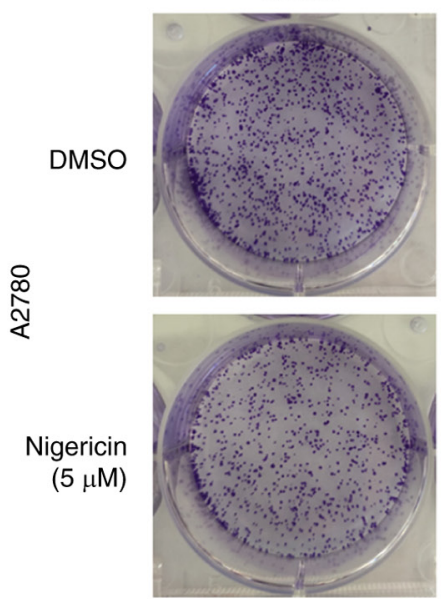

Cisplatin $(5 \mu \mathrm{M})$
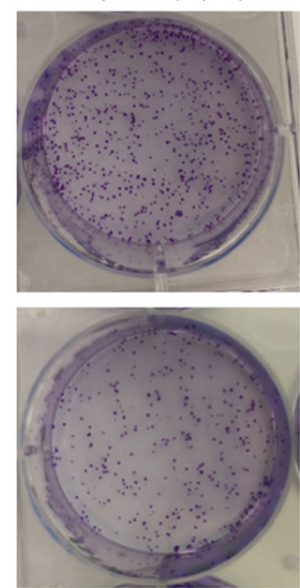

Cisplatin $(5 \mu \mathrm{M})$
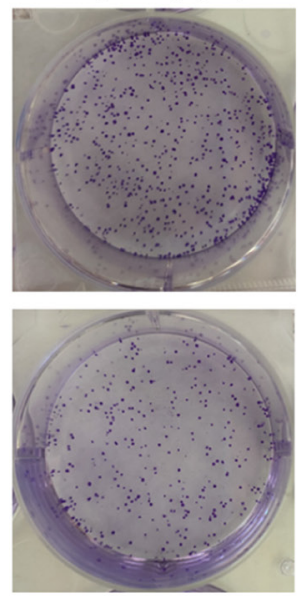

Cisplatin $(20 \mu \mathrm{M})$
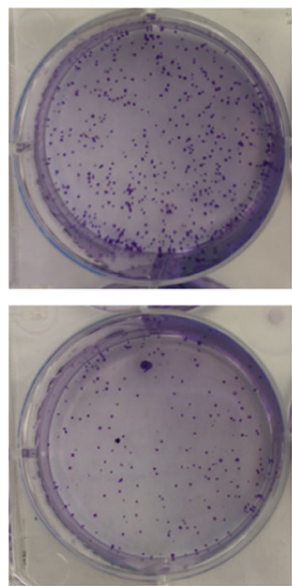

Cisplatin $(20 \mu \mathrm{M})$
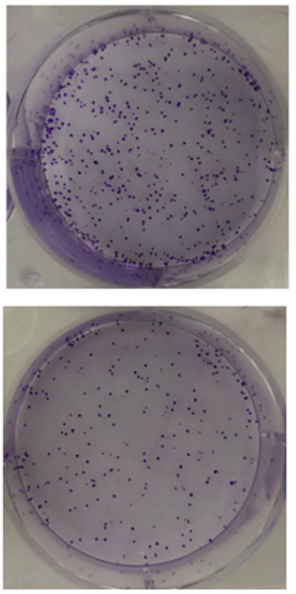
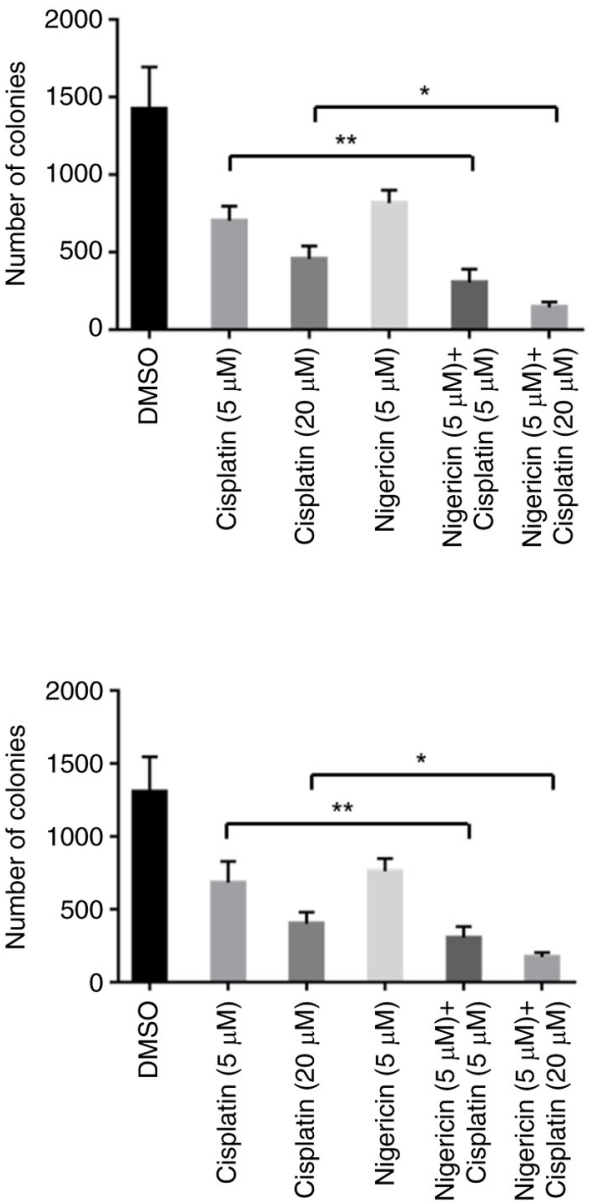

Figure 2. Combination of nigericin with cisplatin enhances the inhibitory effect of cisplatin on the colony formation of epithelial ovarian cancer cells. Representative images of the colony formation assay for (A) SK-OV-3 and (B) A2780 cells after nigericin and cisplatin treatment. Data are presented as the mean $\pm \mathrm{SD}$ of triplicate experiments. ${ }^{*} \mathrm{P}<0.05$ and ${ }^{* *} \mathrm{P}<0.01$

nigericin can inhibit the EMT process during cell invasion and metastasis (17), indicating that nigericin might be an effective chemotherapeutic drug in patients with metastatic EOC. However, to the best of our knowledge, the potential inhibitory effect of nigericin combined with cisplatin on EOC cells has not been studied comprehensively.

In the present study, the combined use of nigericin and cisplatin exhibited enhanced effects in the inhibition of the migration and colony formation of EOC cells. This was mainly due to the inhibitory effect of nigericin on the Wnt/ $\beta$-catenin signalling pathway. In addition, combination treatment exhibited more significant inhibitory effects on the $\mathrm{Wnt} / \beta$-catenin signalling pathway compared with single drug treatment. In terms of the molecular mechanism, nigericin inhibited slug expression by promoting slug SUMOylation, which suppressed the activation of the $\mathrm{Wnt} / \beta$-catenin signalling pathway. In the rescue experiment, slug overexpression reduced the inhibitory effect of nigericin on the Wnt/ $\beta$-catenin signalling pathway, as well as the inhibition of migration and colony formation of EOC cells. Therefore, combination treatment with two drugs could have an improved effect in EOC therapy.

However, drugs with the same molecular mechanism are not recommended (4). A meta-analysis that used individual patient data from random control tests compared single-agent platinum with a platinum-combination in sensitive recurrent EOC (7,8,22-25). The results revealed that combination-platinum chemotherapy may improve the overall survival and progression-free survival; however, platinum combinations inevitably cause greater toxicity in some patients with cancer. Furthermore, combination-platinum chemotherapy is only performed for platinum-sensitive EOC, which is more likely to develop platinum resistance (8). The combination of different mechanism drugs could inhibit tumour progress via more than one pathway, which could be an improved strategy for drug development. The present results suggested that slug might be the potential molecular target of nigericin, and was also involved in the combined effect of nigericin and cisplatin in EOC cells. Moreover, the mechanism of cisplatin is generating unrepairable DNA lesions, which may be different from that of nigericin.

Slug is an EMT-related gene that triggers the initial phases of the EMT process (26-28) via transcriptional reprogramming (29-31). As a major molecular mechanism of epithelial cancer development, EMT has been considered the footstone for metastasis and invasion during the oncogenic process (32-34). The present study not only demonstrated that nigericin could 


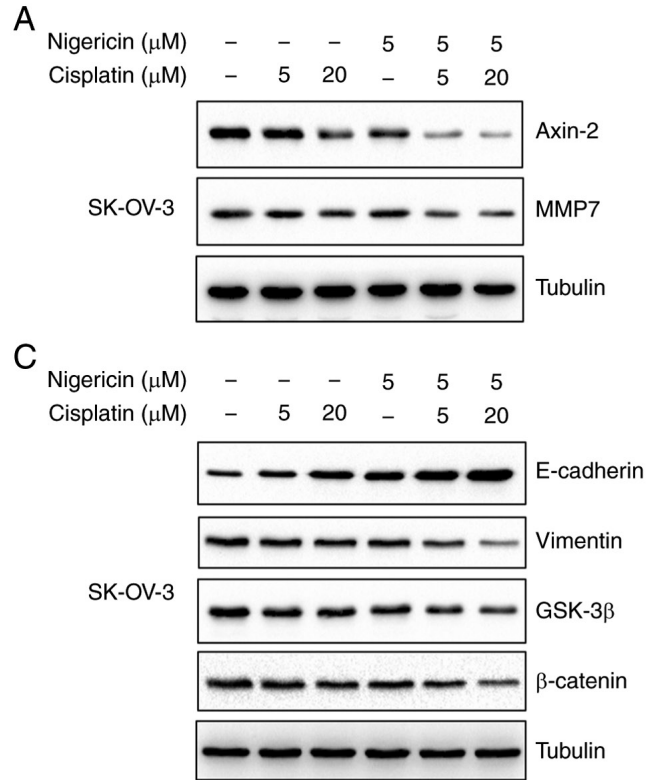

A

Nigericin $(\mu \mathrm{M}) \quad-\quad-\quad-\quad 5 \quad 5$

Cisplatin $(\mu \mathrm{M}) \quad-\quad \begin{array}{llllll}5 & 20 & - & 5 & 20\end{array}$

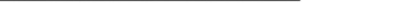

E

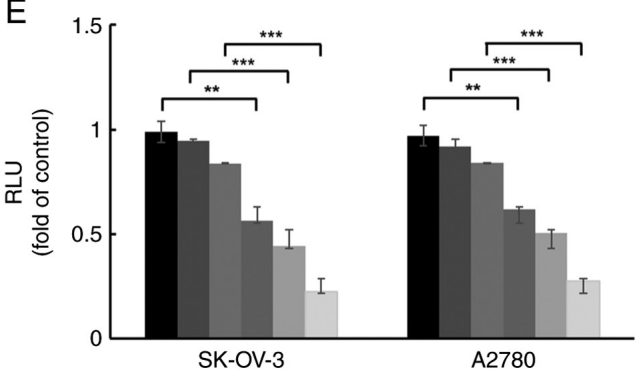

Nigericin $(\mu M) \quad-\quad-\quad-\quad 5 \quad 5 \quad 5$

Cisplatin $(\mu \mathrm{M}) \quad-\quad \begin{array}{llllll}5 & 20 & - & 5 & 20\end{array}$

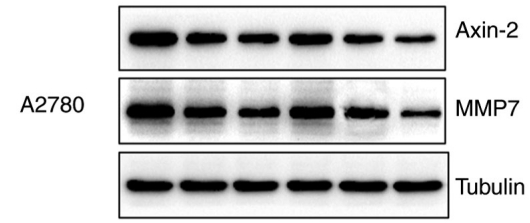

D

Nigericin $(\mu \mathrm{M}) \quad-\quad-\quad-\quad 5 \quad 5 \quad 5$

Cisplatin $(\mu \mathrm{M}) \quad-\quad \begin{array}{llllll}5 & 20 & - & 5 & 20\end{array}$

A2780

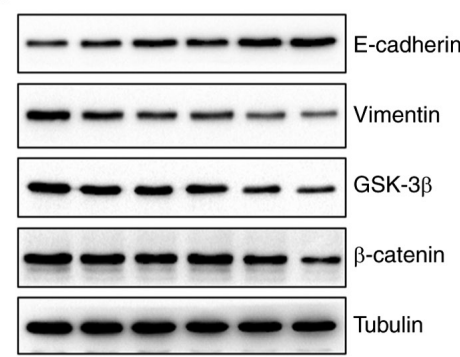

- DMSO

- Cisplatin $(5 \mu \mathrm{M})$

- Cisplatin (20 $\mu \mathrm{M})$

- Nigericin $(5 \mu \mathrm{M})+\mathrm{DMSO}$

- Nigericin $(5 \mu \mathrm{M})+$ Cisplatin $(5 \mu \mathrm{M})$

Nigericin $(5 \mu \mathrm{M})+$ Cisplatin $(20 \mu \mathrm{M})$

Figure 3. Nigericin combined with cisplatin regulates MMP expression and inhibits the Wnt/ $\beta$-catenin signalling pathway in epithelial ovarian cancer cells Western blot analysis of (A) SK-OV-3 and (B) A2780 cells treated with different concentrations of cisplatin and nigericin for $12 \mathrm{~h}$ was performed to evaluate the protein expression levels of Axin-2 and MMP7. Tubulin was used as a standard. Expression levels of Wnt/ $\beta$-catenin signalling pathway-associated proteins, such as E-cadherin, GSK- $\beta, \beta$-catenin and Vimentin, were assessed by western blotting in (C) SK-OV-3 and (D) A2780 cells. (E) Luciferase reporter assays demonstrated that the activation effect of the Wnt/ $\beta$-catenin pathway was markedly reduced by adding nigericin, compared with no nigericin in both SK-OV-3 and A2780 cells. RLU, relative luciferase units. ${ }^{* *} \mathrm{P}<0.01$ and ${ }^{* * *} \mathrm{P}<0.001$.

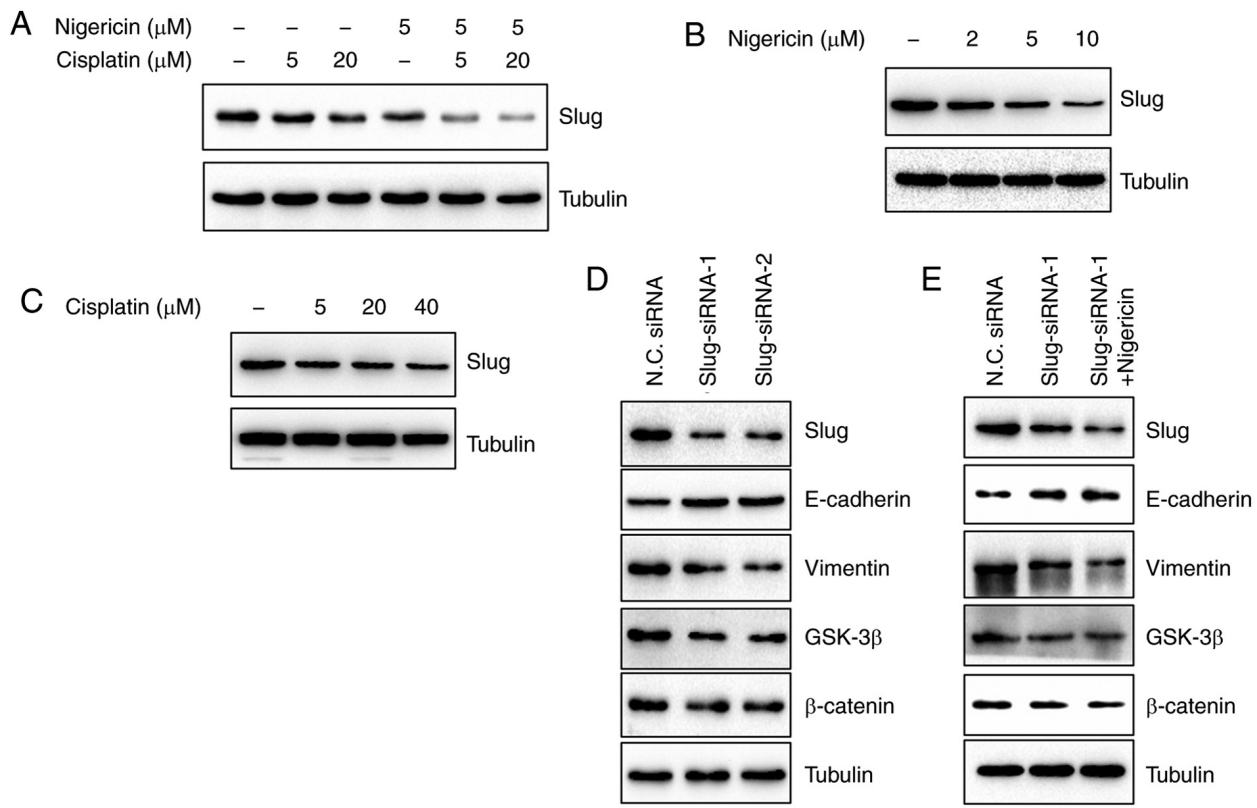

Figure 4. Nigericin enhances the inhibitory effect of cisplatin on slug expression in epithelial ovarian cancer cells. Slug expression in SK-OV-3 cells after treatment with (A) the combination of nigericin and cisplatin, (B) nigericin only and (C) cisplatin only. (D) Effects of siRNA-induced slug knockdown on the expression levels of proteins associated with the Wnt signalling pathway. (E) Comparison of the effects of siRNA-induced slug knockdown and its combination with nigericin $(5 \mu \mathrm{M})$ treatment on the expression levels of proteins associated with the Wnt signalling pathway. N.C., negative control; siRNA, small interfering RNA. 

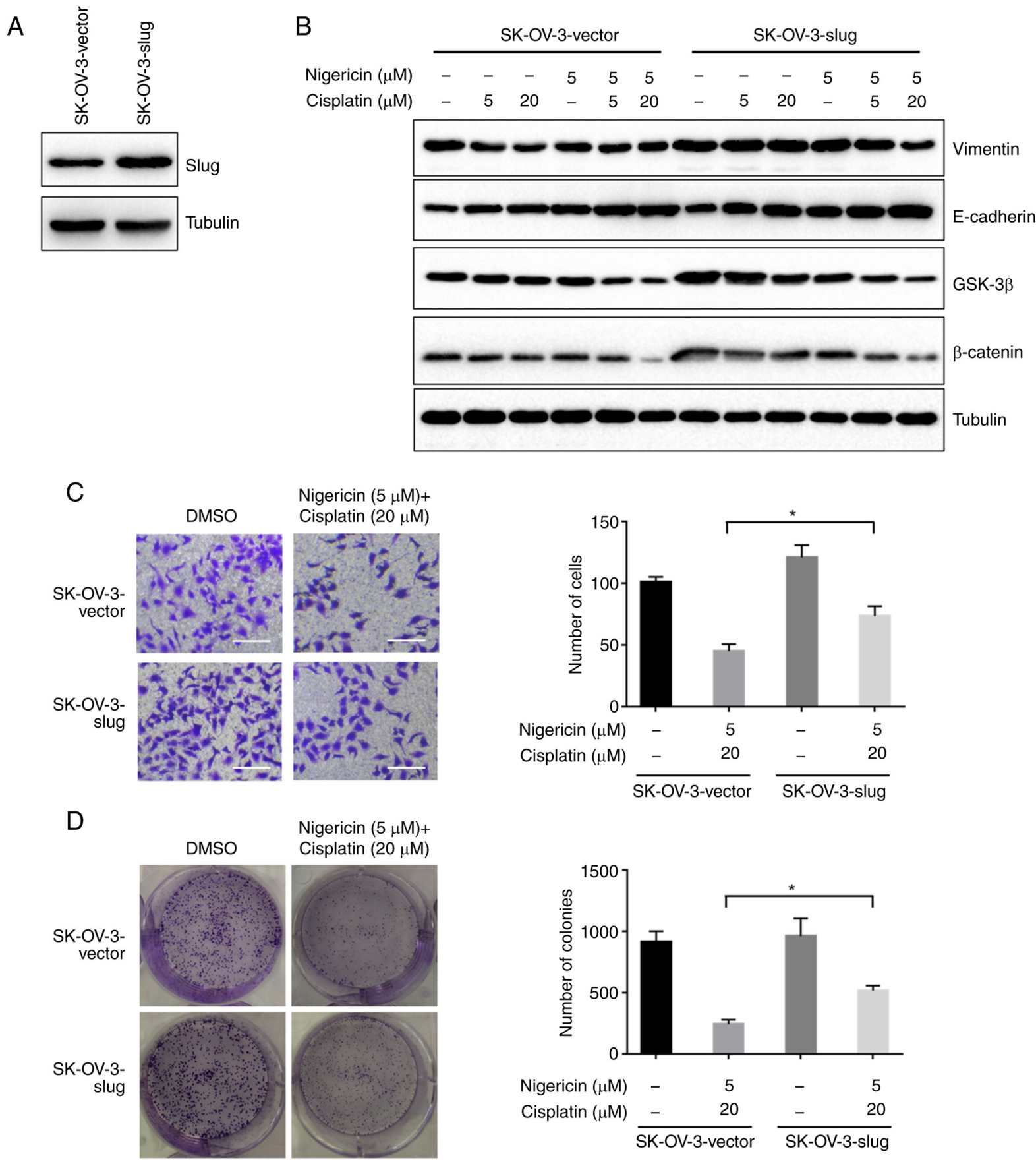

Figure 5. Overexpression of slug rescues the phenotype induced by the treatment with nigericin and cisplatin combined in SK-OV-3 cells. (A) Slug expression was determined by western blotting. Tubulin was used as a control. (B) Effect of slug on the Wnt/ $\beta$-catenin signal pathway in the presence of nigericin was examined by western blotting. Overexpression of slug rescued the inhibitory effect of nigericin and cisplatin on (C) migration and (D) colony formation. Scale bar, $25 \mu \mathrm{m} .{ }^{*} \mathrm{P}<0.01$ vs. vector.

A

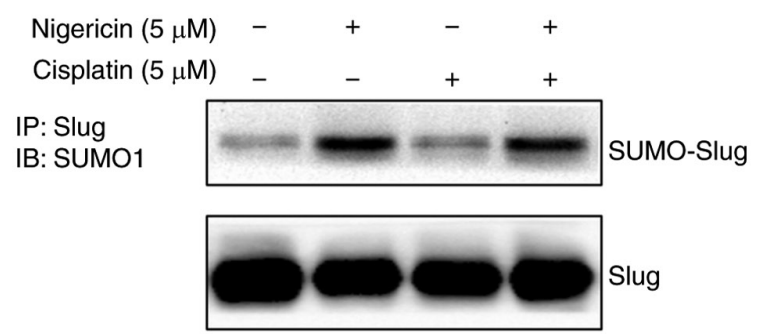

B

Nigericin $(5 \mu \mathrm{M})$

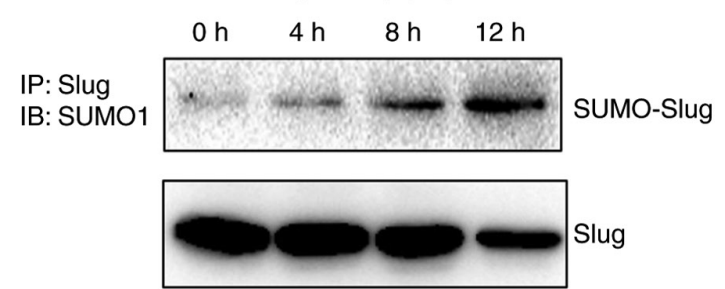

Figure 6. Nigericin enhances the SUMOylation of slug. (A) SUMOylation of slug was increased following treatment with nigericin but not cisplatin in SK-OV-3 cells. (B) Nigericin exhibited a time-dependent effect on SUMOylation. IB, the antibody used to blot the membrane; IP, the antibody used to pull down in cell lysate; SUMO1, small ubiquitin-like modifier 1. 
inhibit the EMT process by increasing E-cadherin expression and reducing vimentin expression by inhibiting slug, which was consistent with previous studies $(17,35)$, but also revealed the more significant synergistic effect in the combined treatment with cisplatin. Considering that slug is a transcription factor that can be regulated by the Wnt/ $\beta$-catenin signalling pathway (19), the present results suggested that crosstalk might occur between the Wnt signalling cascade and the DNA repair pathways. To the best of our knowledge, this report was the first to address the synergistic effect of the combined treatment with nigericin and cisplatin in cancer cells. Nigericin could also enhance the SUMOylation of slug, which might be the underlying mechanism of the synergistic effect. Aside from ubiquitination, SUMOylation mediated by SUMO1 or SUMO2/3 is another gene regulation pattern at the post-translational level in the regulation of kinase activity, protein trafficking and stability $(36,37)$. On the one hand, pathogens could use the characteristics of proteins to degrade important kinase or transcription factors by enhancing their SUMOylation, which may serve a key role in pathogen-related oncogenic transformation (38). On the other hand, such characteristics could also be used to develop drugs to inhibit oncogene expression by enhancing SUMOylation. Although interesting results have been revealed, the potential crosstalk of the related pathways and the precise mechanism of the synergistic effect of combined nigericin and cisplatin treatment remain to be explored.

In conclusion, the present data revealed that nigericin combined with cisplatin might enhance the in vitro inhibitory effect of cisplatin on EOC metastasis by inhibiting slug expression via the $\mathrm{Wnt} / \beta$-catenin signalling pathway. In the future, the underlying mechanisms of the synergistic and in vivo effects of the combined therapy need to be elucidated in detail.

\section{Acknowledgements}

Not applicable.

\section{Funding}

The present study was supported by the Shandong Natural Science Foundation (grant no. ZR2017PH029).

\section{Availability of data and materials}

All data generated or analyzed during this study are included in this published article.

\section{Authors' contributions}

SY and SZ conceived and designed the experiments. BZ, JL, SY and $\mathrm{SZ}$ confirm the authenticity of all the raw data. BZ, CW, JL and SY performed the experiments. BZ, XL and BW analysed the data. JL and SY contributed reagents/materials/analysis tools. BZ, CW and XL wrote the manuscript. XL and SZ reviewed the manuscript. All authors read and approved the final manuscript.

\section{Ethics approval and consent to participate}

Not applicable.

\section{Patient consent for publication}

Not applicable.

\section{Competing interests}

The authors declare that they have no competing interests.

\section{References}

1. Chen W, Zheng R, Baade PD, Zhang S, Zeng H, Bray F, Jemal A, Yu XQ and He J: Cancer statistics in China, 2015. CA Cancer J Clin 66: 115-132, 2016.

2. Reid BM, Permuth JB and Sellers TA: Epidemiology of ovarian cancer: A review. Cancer Biol Med 14: 9-32, 2017.

3. Colombo N, Parma G, Zanagnolo V and Insinga A: Management of ovarian stromal cell tumors. J Clin Oncol 25: 2944-2951, 2007.

4. Damia $\mathrm{G}$ and Broggini M: Platinum resistance in ovarian cancer: Role of DNA repair. Cancers (Basel) 11: 119, 2019.

5. Tomao F, D'Incalci M, Biagioli E, Peccatori FA and Colombo N: Restoring platinum sensitivity in recurrent ovarian cancer by extending the platinum-free interval: Myth or reality? Cancer 123: 3450-3459, 2017.

6. Lheureux S, Gourley C, Vergote I and Oza AM: Epithelial ovarian cancer. Lancet 393: 1240-1253, 2019.

7. RajaFA,CounsellN,Colombo N,Pfisterer J,du Bois A,Parmar MK, Vergote IB, Gonzalez-Martin A, Alberts DS, Plante M, et al: Platinum versus platinum-combination chemotherapy in platinum-sensitive recurrent ovarian cancer: A meta-analysis using individual patient data. Ann Oncol 24: 3028-3034, 2013.

8. Parmar MK, Ledermann JA, Colombo N, du Bois A, Delaloye JF Kristensen GB, Wheeler S, Swart AM, Qian W, Torri V, et al: Paclitaxel plus platinum-based chemotherapy versus conventional platinum-based chemotherapy in women with relapsed ovarian cancer: The ICON4/AGO-OVAR-2.2 trial. Lancet 361: 2099-2106, 2003.

9. Borella F, Ghisoni E, Giannone G, Cosma S, Benedetto C, Valabrega $\mathrm{G}$ and Katsaros D: Immune checkpoint inhibitors in epithelial ovarian cancer: An overview on efficacy and future perspectives. Diagnostics (Basel) 10: 146, 2020.

10. Kaushik V, Yakisich JS, Kumar A, Azad N and Iyer AKV: Ionophores: Potential use as anticancer drugs and chemosensitizers. Cancers (Basel) 10: 360, 2018.

11. Harned RL, Hidy PH, Corum CJ and Jones KL: Nigericin a new crystalline antibiotic from an unidentified Streptomyces. Antibiot Chemother (Northfield) 1: 594-596, 1951.

12. Liu F, Li W, Hua S, Han Y, Xu Z, Wan D, Wang Y, Chen W, Kuang Y, Shi J and Zhi Q: Nigericin exerts anticancer effects on human colorectal cancer cells by inhibiting wnt/ $\beta$-catenin signaling pathway. Mol Cancer Ther 17: 952-965, 2018.

13. Yakisich JS, Azad N, Kaushik V, O'Doherty GA and Iyer AK: Nigericin decreases the viability of multidrug-resistant cancer cells and lung tumorspheres and potentiates the effects of cardiac glycosides. Tumour Biol 39: 1010428317694310, 2017.

14. Boesch M, Zeimet AG, Rumpold H, Gastl G, Sopper S and Wolf D: Drug transporter-mediated protection of cancer stem cells from ionophore antibiotics. Stem Cells Transl Med 4: 1028-1032, 2015.

15. Deng CC, Liang Y, Wu MS, Feng FT, Hu WR, Chen LZ, Feng QS, Bei JX and Zeng YX: Nigericin selectively targets cancer stem cells in nasopharyngeal carcinoma. Int J Biochem Cell Biol 45: 1997-2006, 2013.

16. Hrgovic I, Glavic Z, Kovacic Z, Mulic S, Zunic L and Hrgovic Z: Repeated administration of inhibitors for ion pumps reduce markedly tumor growth in vivo. Med Arch 68: 76-78, 2014.

17. Wang W, Zhao Y, Yao S, Cui X, Pan W, Huang W, Gao J, Dong T and Zhang S: Nigericin inhibits epithelial ovarian cancer metastasis by suppressing the cell cycle and epithelial-mesenchymal transition. Biochemistry (Mosc) 82: 933-941, 2017.

18. Karam A and Dorigo O: MMPs in ovarian cancer as therapeutic targets. Anticancer Agents Med Chem 12: 764-772, 2012.

19. Nieszporek A, Skrzypek K, Adamek G and Majka M: Molecular mechanisms of epithelial to mesenchymal transition in tumor metastasis. Acta Biochim Pol 66: 509-520, 2019. 
20. Kulshrestha A, Katara GK, Ibrahim SA, Riehl V, Sahoo M, Dolan J, Meinke KW, Pins MR and Beaman KD: Targeting V-ATpase isoform restores cisplatin activity in resistant ovarian cancer: Inhibition of autophagy, endosome function, and ERK/MEK pathway. J Oncol 2019: 2343876, 2019.

21. Galluzzi L, Vitale I, Michels J, Brenner C, Szabadkai G, Harel-Bellan A, Castedo M and Kroemer G: Systems biology of cisplatin resistance: Past, present and future. Cell Death Dis 5: e1257, 2014.

22. Pfisterer J, Plante M, Vergote I, du Bois A, Hirte H, Lacave AJ, Wagner U, Stahle A, Stuart G, Kimmig R, et al: Gemcitabine plus carboplatin compared with carboplatin in patients with platinum-sensitive recurrent ovarian cancer: An intergroup trial of the AGO-OVAR, the NCIC CTG, and the EORTC GCG. J Clin Oncol 24: 4699-4707, 2006.

23. Gonzalez-Martin AJ, Calvo E, Bover I, Rubio MJ, Arcusa A, Casado A, Ojeda B, Balana C, Martinez E, Herrero A, et al Randomized phase II trial of carboplatin versus paclitaxel and carboplatin in platinum-sensitive recurrent advanced ovarian carcinoma: A GEICO (Grupo Espanol de Investigacion en Cancer de Ovario) study. Ann Oncol 16: 749-755, 2005.

24. Alberts DS, Liu PY, Wilczynski SP, Clouser MC, Lopez AM, Michelin DP, Lanzotti VJ and Markman M; Southwest Oncology G: Randomized trial of pegylated liposomal doxorubicin (PLD) plus carboplatin versus carboplatin in platinum-sensitive (PS) patients with recurrent epithelial ovarian or peritoneal carcinoma after failure of initial platinum-based chemotherapy (Southwest Oncology Group Protocol S0200). Gynecol Oncol 108: 90-94, 2008.

25. Bolis G, Scarfone G, Giardina G, Villa A, Mangili G, Melpignano M, Presti M, Tateo S, Franchi M, Parazzini F, et al: Carboplatin alone vs carboplatin plus epidoxorubicin as second-line therapy for cisplatin-or carboplatin-sensitive ovarian cancer. Gynecol Oncol 81: 3-9, 2001.

26. Savagner P, Yamada KM and Thiery JP: The zinc-finger protein slug causes desmosome dissociation, an initial and necessary step for growth factor-induced epithelial-mesenchymal transition. J Cell Biol 137: 1403-1419, 1997.

27. De Craene B and Berx G: Regulatory networks defining EMT during cancer initiation and progression. Nat Rev Cancer 13: 97-110, 2013
28. Phillips S and Kuperwasser C: SLUG: Critical regulator of epithelial cell identity in breast development and cancer. Cell Adh Migr 8: 578-587, 2014

29. Ye X, Tam WL, Shibue T, Kaygusuz Y, Reinhardt F, Ng Eaton E and Weinberg RA: Distinct EMT programs control normal mammary stem cells and tumour-initiating cells. Nature 525: 256-260, 2015.

30. Fang JH, Zhou HC, Zhang C, Shang LR, Zhang L, Xu J, Zheng L, Yuan Y, Guo RP, Jia WH, et al: A novel vascular pattern promotes metastasis of hepatocellular carcinoma in an epithelial-mesenchymal transition-independent manner. Hepatology 62: 452-465, 2015.

31. Liu X, Sun H, Qi J, Wang L, He S, Liu J, Feng C, Chen C, Li W, Guo Y, et al: Sequential introduction of reprogramming factors reveals a time-sensitive requirement for individual factors and a sequential EMT-MET mechanism for optimal reprogramming. Nat Cell Biol 15: 829-838, 2013.

32. Kalluri R and Weinberg RA: The basics of epithelial-mesenchymal transition. J Clin Invest 119: 1420-1428, 2009.

33. Lamouille S, Xu J and Derynck R: Molecular mechanisms of epithelial-mesenchymal transition. Nat Rev Mol Cell Biol 15: 178-196, 2014.

34. Nieto MA, Huang RY, Jackson RA and Thiery JP: Emt: 2016. Cell 166: 21-45, 2016

35. Lu D, Choi MY, Yu J, Castro JE, Kipps TJ and Carson DA: Salinomycin inhibits Wnt signaling and selectively induces apoptosis in chronic lymphocytic leukemia cells. Proc Natl Acad Sci USA 108: 13253-13257, 2011.

36. Geiss-Friedlander R and Melchior F: Concepts in sumoylation: A decade on. Nat Rev Mol Cell Biol 8: 947-956, 2007.

37. Kho C, Lee A, Jeong D, Oh JG, Chaanine AH, Kizana E, Park WJ and Hajjar RJ: SUMO1-dependent modulation of SERCA2a in heart failure. Nature 477: 601-605, 2011

38. Chand V, John R, Jaiswal N, Johar SS and Nag A: High-risk HPV16E6 stimulates hADA3 degradation by enhancing its SUMOylation. Carcinogenesis 35: 1830-1839, 2014. International (CC BY-NC-ND 4.0) License. 